
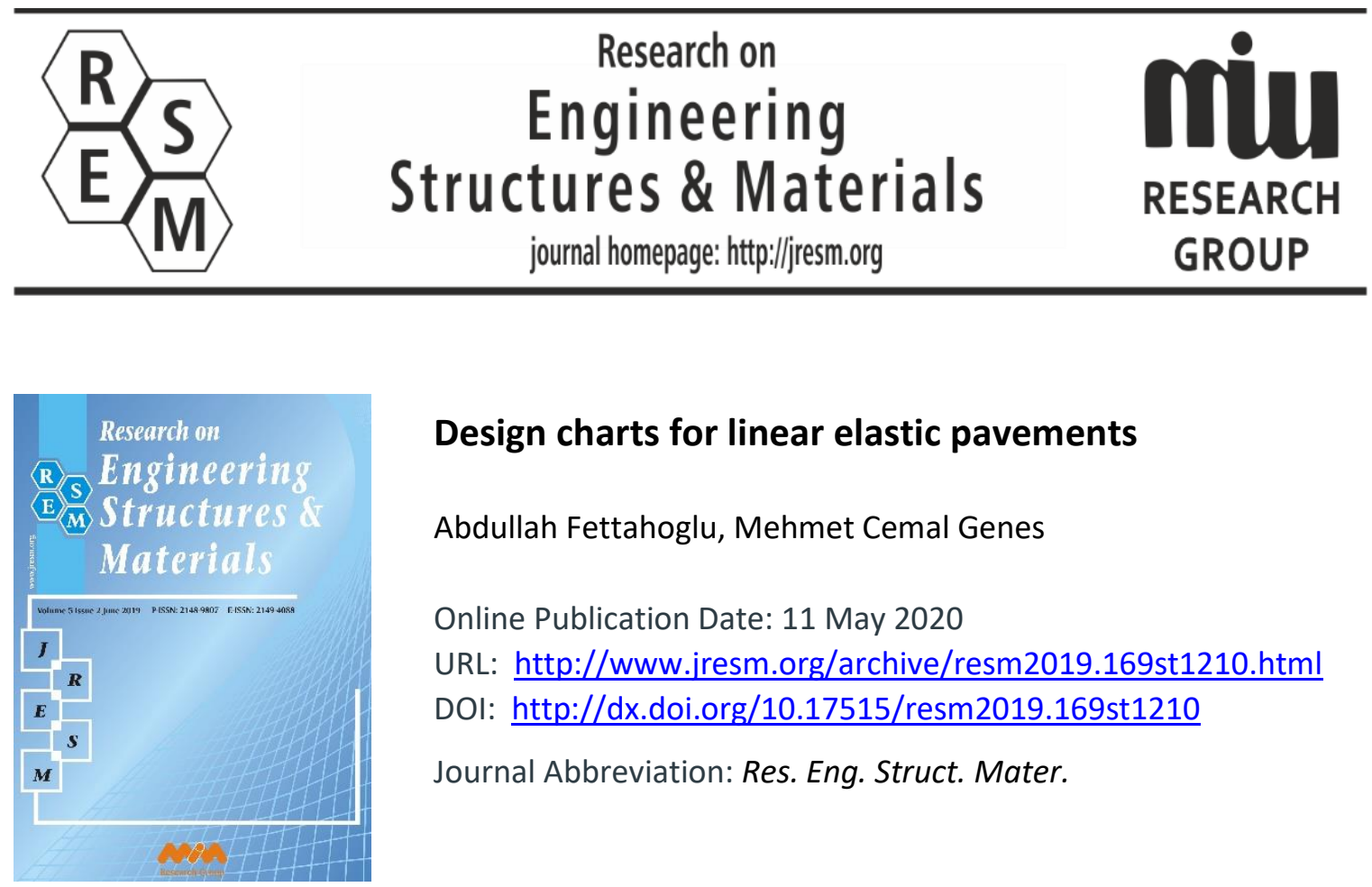

\title{
Design charts for linear elastic pavements
}

Abdullah Fettahoglu, Mehmet Cemal Genes

Online Publication Date: 11 May 2020

URL: http://www.jresm.org/archive/resm2019.169st1210.html

DOI: http://dx.doi.org/10.17515/resm2019.169st1210

Journal Abbreviation: Res. Eng. Struct. Mater.

\section{To cite this article}

Fettahoglu A, Genes MC. Design charts for linear elastic pavements. Res. Eng. Struct. Mater., 2020; 6(4): 385-409.

\section{Disclaimer}

All the opinions and statements expressed in the papers are on the responsibility of author(s) and are not to be regarded as those of the journal of Research on Engineering Structures and Materials (RESM) organization or related parties. The publishers make no warranty, explicit or implied, or make any representation with respect to the contents of any article will be complete or accurate or up to date. The accuracy of any instructions, equations, or other information should be independently verified. The publisher and related parties shall not be liable for any loss, actions, claims, proceedings, demand or costs or damages whatsoever or howsoever caused arising directly or indirectly in connection with use of the information given in the journal or related means.

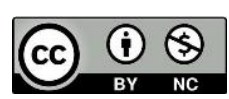

Published articles are freely available to users under the terms of Creative Commons Attribution - NonCommercial 4.0 International Public License, as currently displayed at here (the "CC BY - NC"). 


\title{
Research on Engineering Structures \& Materials \\ journal homepage: http://jresm.org
}

Research Article

\section{Design charts for linear elastic pavements}

\begin{abstract}
Abdullah Fettahoglu*1,a, Mehmet Cemal Genes ${ }^{2, b}$
${ }^{1}$ Department of Civil Engineering, Usak University, Usak, Turkey.

${ }^{2}$ Department of Civil Engineering, Eastern Mediterranean University, Famagusta, Northern Cyprus Turkish Republic

Article Info

Article history:

Received 10 Dec 2019

Revised 24 Apr 2020

Accepted 05 May 2020

Keywords:

Linear elastic

pavements;

Design charts;

Hand calculations;

Concrete pavements

Abstract

Deformation of most pavements is practically inelastic. Thus, the exact calculation of pavement deformation often requires use of a damage evaluation law to characterize the stress-strain relationship mathematically. Asphalt, polymer, and reinforced concrete are all examples of such pavements. However, concrete pavements without reinforcement are generally assumed to behave linear elastic. Concrete pavements without reinforcement are used sometimes as permanent pavements with dowels such as airport apron pavement, but sometimes they are used as temporary pavements during the mobilization or initial phases of new construction projects as well. When used as permanent pavements, their design is performed similar to rigid pavements, which has international acceptance by highway engineers, or by finite element analysis. When used as temporary works during the mobilization phase, or when a road is urgently required on a construction site, their design is often problematic, because advanced highway design or finite element analysis might be momently unavailable. A rapid, conservative, and reliable hand calculation method for temporary concrete pavements without reinforcement is therefore required. In this study, design charts are provided to allow hand calculations of temporary concrete pavements. In addition, a numerical example is solved to illustrate the use of derived charts. The effects of certain parameters on the stress behavior of concrete pavements are also investigated.
\end{abstract}

(C) 2020 MIM Research Group. All rights reserved.

\section{Introduction}

In this study, some hand calculation charts are derived to enable quick and conservative design of linear elastic rigid pavements, such as temporary concrete pavements without reinforcement, of the type frequently used at the mobilization phase of construction. The design of a linear elastic rigid pavement is based on the maximum stress developed in the pavement itself and in its base. The source of these stresses relates of course to the heaviest wheel load on the top of the pavement. As a result, the maximum stress develops in the contact zone between the wheel and the pavement. The first stage is therefore the calculation of this maximum (or peak) stress, which is necessary to determine the required strength of pavement. At the same time, the stresses induced by the wheel load are dispersed through the thickness of the pavement, and a reduced, dispersed stress is then obtained at the base of the pavement. The maximum value of these vertical stresses must be less than the bearing capacity of the soil. This leads to the second consideration, which is the calculation of the maximum stress at the pavement base in order to determine the pavement thickness required. Starting from the beginning, Groenendijk (1998), Pottinger (1992), Tielking (1994), De Beer (1996), and Jong (2007) [1-5] investigated the contact stress developed between the wheel and the pavement. Of all, Groenendijk [1] derived formulas to determine the maximum stress between the wheel and the pavement, also referred to as the "Footprint pressure" in the literature. This subject is

\footnotetext{
${ }^{*}$ Corresponding author: abdullah.fettahoglu@usak.edu.tr

a orcid.org/0000-0001-5759-1794; b orcid.org/0000-0002-9052-7361

DOI: http://dx.doi.org/10.17515/resm2019.169st1210
}

Res. Eng. Struct. Mat. Vol. 6 Iss. 4 (2020) 385-409 
discussed in the first section after the introduction. The issue of the second maximum stress at the base of the pavement is evaluated in the subsequent sections. A $45^{\circ}$ stress dispersal in the direction of pavement thickness is generally assumed to calculate that second stress. This assumption is applied in many engineering calculations, and is also supported in the literature [6]. However, it is still unclear whether this proposed $45^{\circ}$ stress dispersion and the uniform vertical stress distribution is appropriate. Unfortunately, stress dispersal through pavement thickness is less investigated by the researchers. Among that less data available in the literature, Li et al. [7] investigated the stresses in the pavement for the safety of underground pipelines. They studied a range of parameters in an attempt to reduce the stress in the base of the pavement and in the top of the infrastructure pipe and revealed that the burial depth of the pipes should be increased to provide acceptable levels of stress above the pipes. Therefore, the aim of the present study is to investigate the magnitude and shape of the dispersed wheel load in the pavement base. First, a finite element (FE) model of the pavement and wheel model is developed using ANSYS [8]. Second, pavement is assumed to be linear elastic and wheel is assumed conservatively to be a static load rather than a moving load. Third, the possible parameters that could affect the value and shape of the dispersed load at the pavement base are selected. Fourth, the shape and value of the dispersed load at the pavement base is determined by means of FE analysis. Fifth, verification of the FE model is undertaken using Boussinesq equation. Sixth, the effects of the parameters on the dispersed stress are assessed, and finally design charts are derived to estimate the magnitude and shape of the dispersed stress at the pavement base.

\section{Determination of the Contact Stress (First Maximum Stress) between the Wheel and Pavement}

Groenendijk [1] performed extensive research on the contact stresses between tyre and pavement. He measured the footprint pressure using the Vehicle-Road Surface Pressure Transducer Array (VRSPTA) system. VRSPTA measures the stresses between relatively slow moving free-rolling tyres and the road surface. It measures the vertical stresses, as well as longitudinal and lateral shear stresses. Groenendijk [1] also performed tests for various combinations of wheel load, tyre inflation pressure, and wheel speed for two wide-base single tyres (type C) [6]. With the VRSPTA system, it is possible to measure stress patterns at the interface between tyre and pavement. Fig. 1 shows an example of a measured 3D stress pattern for a 425/65 R22.5 tyre [6] for an inflation pressure of $0.7 \mathrm{MPa}$, loaded at $100 \mathrm{kN}$, moving at 0.3 $\mathrm{m} / \mathrm{s}$ [5].

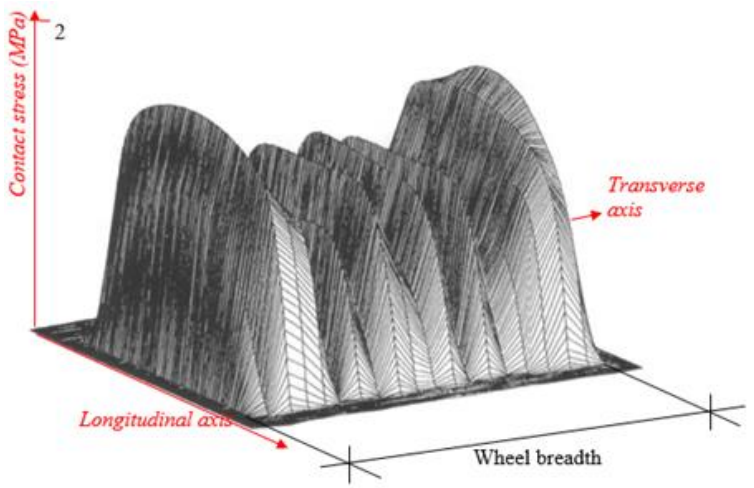

Fig. 1 Example of measuring contact stress using VRSPTA [5]. 
Groenendijk formulated the following conclusions from his research [5]:

1. The wheel load mainly governs the stresses at the tyre edges, while the tyre pressure governs the stresses at the center of the tyre.

2. The tyre/pavement contact area can be modeled as a rectangle as wide as the tyre tread area, and with a length that depends on the load and inflation pressure. For stress modeling, this area should be divided into three zones in the transverse direction: Two edge zones each $20 \%$ of the tyre width, and one middle zone covering the remaining $60 \%$.

3. The vertical contact stresses may be treated as uniformly distributed loads, but generally with different values for the middle and edge zones.

Groenendijk derived equations for the footprint (contact) stress:

$$
\begin{aligned}
& \sigma_{z ; \text { ave } ; \text { middle }}=422-1.20 \cdot F+4.60 \cdot 10^{-3} \cdot F \cdot p+0.322 \cdot p+8.60 \cdot v \\
& \sigma_{z ; \text { ave } \text { edge }}=85.5+9.25 \cdot F+0.290 \cdot p+1.29 \cdot v
\end{aligned}
$$

where:

$F=$ Wheel load $(\mathrm{kN})$

$p=$ Tyre inflation pressure $(\mathrm{kPa})$

$v=$ Wheel speed $(\mathrm{m} / \mathrm{s})$

$\sigma_{z ; \text { ave; } m i d d l e}=$ Average vertical contact stress over the middle $60 \%$ of the tyre width (breadth) and the full tyre footprint length $(\mathrm{kPa})$

$\sigma_{z ; a v e ; e d g e}=$ Average vertical contact stress over the edges $2 \times 20 \%$ of the tyre width and the full tyre footprint length $(\mathrm{kPa})$.

Using the load, the inflation pressure, and the velocity, contact stresses can be calculated. The equations derived by Groenendijk are based on measurements for wide-base tyres (type C). It may be assumed that these equations are also valid for the single (type A) and the double (type B) tyres, because these tyre types differ only slightly from the super single (type C) [5]. Fortunately, Jong [5] proved in his thesis that the wheel contact areas given in EC3 [6] are acceptable by means of the Lintrack measurement system used by Jong [5].

If the velocity and tyre pressure in Eq.1 and Eq. 2 are conservatively replaced with $0 \mathrm{~m} / \mathrm{s}$ and $0.9 \mathrm{kPa}$ respectively, Eq. 3 and Eq. 4 are obtained as follows:

$$
\begin{aligned}
& \sigma_{z ; \text { ave;middle }}=422.3-1.2042 \cdot \mathrm{F} \\
& \sigma_{z ; \text { ave } ; \text { edge }}=85.761+9.25 \cdot \mathrm{F}
\end{aligned}
$$

The variation of contact stresses on edge and middle zones depending on wheel load $(\mathrm{N})$ are given in Fig. 2 using Eq.3 and Eq.4.

Because the method derived here is aimed for the design of temporary concrete pavements, the lowest strength of the pavement can be conservatively taken as $10 \mathrm{MPa}$ (lean concrete). In this case a wheel load or a set of adjacent wheel loads must be $1000 \mathrm{kN}$ to overcome the strength of the concrete and crack the pavement, which is almost impossible in practice. As a result, there is no need to consider the contact stress between the pavement and the wheel in the design of temporary concrete pavements without reinforcement. 


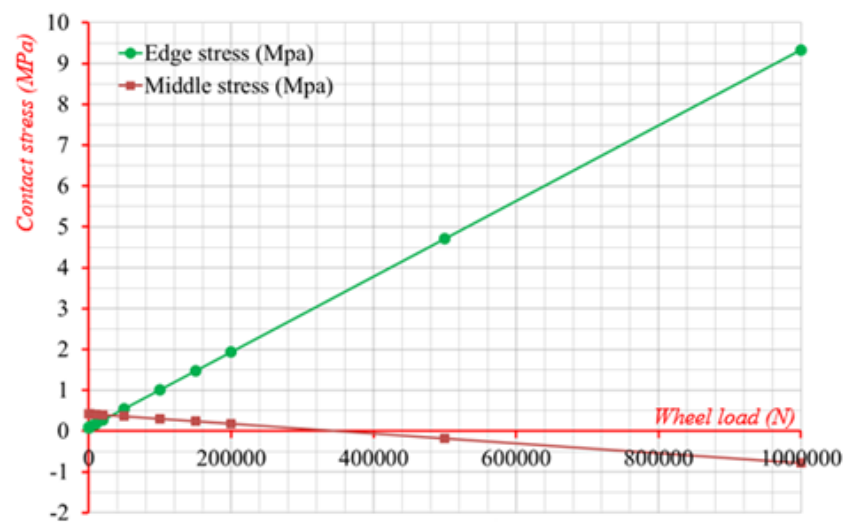

Fig. 2 Variation of edge and middle zone contact stresses according to

Eq.3 and Eq.4.

\section{Determination of the Dispersed Stress (Second Maximum Stress) at the Pavement Base}

The second maximum stress depends on the dispersed stresses at the pavement base, because the wheel-induced stresses might not just be due to a single wheel, but instead, due to a set of wheels. Therefore, it is considered here both the distribution and the maximum of the vertical stress value at the pavement base. If the pavement design is to be performed for more than one wheel, where the wheels are adjacent and interact with each other, the maximum vertical stress can be determined from the superposition of both of the dispersed stresses at the pavement base. To determine the distribution of the dispersed stress at the pavement base, it is first necessary to select the potential parameters influencing the dispersed stress. The effect of these parameters on this distribution is then analyzed separately. Finally, charts are derived for the calculation of the single-wheel load-induced dispersed stress.

\subsection{Definition of Parameters}

The intended parameters shown in Fig. 3 are wheel load $\left(W_{L}\right)$, wheel breadth $\left(W_{B}\right)$, elasticity modulus $\left(E_{P}\right)$, Poisson ratio $\left(V_{P}\right)$, width $\left(W_{P}\right)$ and thickness of pavement $\left(T_{P}\right)$. All parameters and their default values are shown in Fig. 3. Finite element (FE) analysis, termed "reference" analysis, is performed using the default (or initial) parameter values. Then, a single parameter is changed, while keeping the others constant. In this way, the effect of this single parameter on the magnitude and distribution of the dispersed stresses is evaluated.

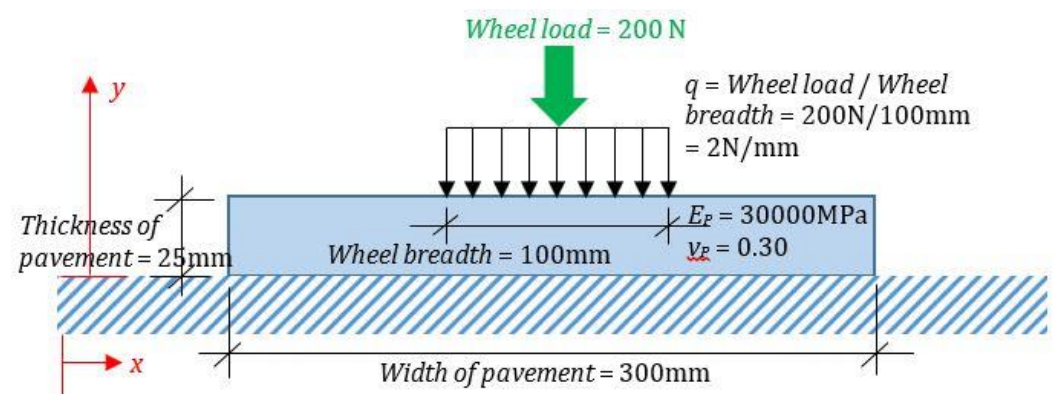

Fig. 3 Default (or initial) values of parameters 


\subsection{FE Model}

The reference FE analysis is used to find the distribution of the dispersed stress at the base of the pavement and additionally in the intermediate layers. The FE model employed in this study is fully restrained against translation and rotation on the pavement base. The number of elements and nodes used in the FE model are 8748 and 9100 respectively. A four-node FE, referred to as SHELL181 in the ANSYS [8] documentation, is used to generate the FE model. Results of the reference FE-analysis, depending on the default values of the parameters are shown in Fig. 4, in which the dispersed stresses (See Fig. 3 for the definitions of the $x$ and $y$-axes) are given for the top, intermediate, and base layers of pavement. The intermediate layers are selected for various elevations (Values of $y$ in Fig. 4 relate to the $y$-axis shown in Fig. 3, not the depths of pavement layers).

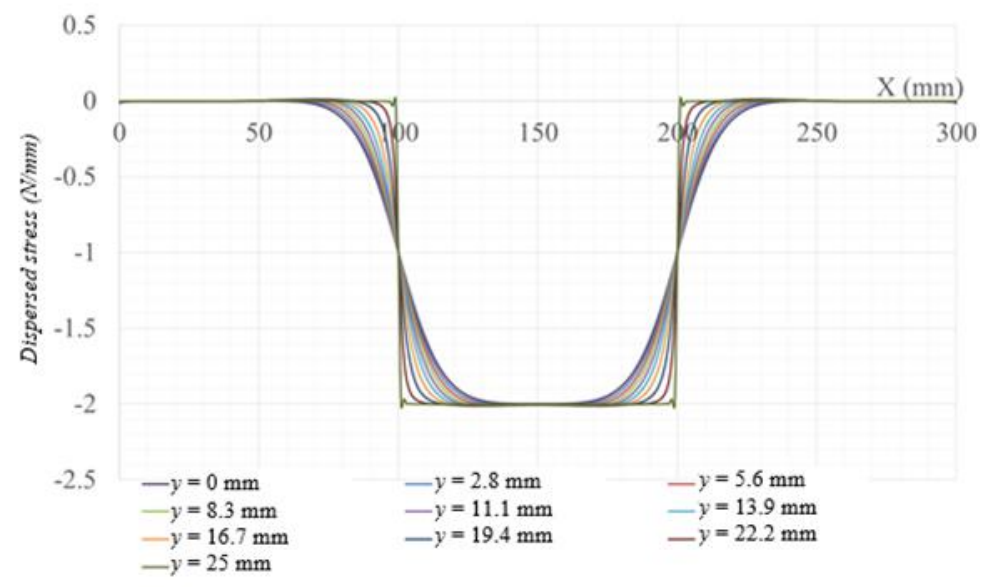

Fig. 4 Dispersed stresses at the top, intermediate layers, and base of pavement.

\subsection{Comparison of FE-Analysis with Boussinesq Equation}

A comparison of FE-analysis with the Boussinesq equation [9] is performed to determine the dispersed stress at intermediate depths in a semi-infinite continuum (semi-space), as shown in Fig. 5.

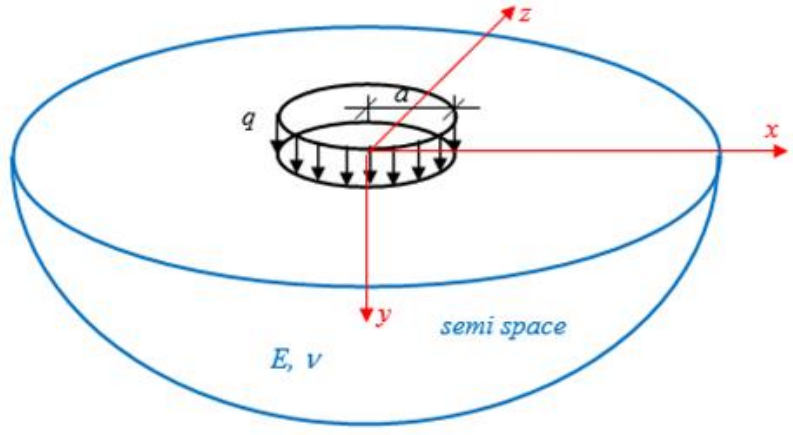

Figure 5. Semi-space with uniform load

The Boussinesq equation for dispersed stress $\left(\sigma_{y}\right)$ provided by Timoshenko and Goodier [9] is 
given below.

$$
\sigma_{y}=q \cdot\left[-1+\frac{y^{3}}{\left(a^{2}+y^{2}\right)^{1.5}}\right]
$$

Using Eq.5 in conjunction with FE results allows comparison between the FE and Boussinesq solutions as shown in Figs. $6 a$ and b.
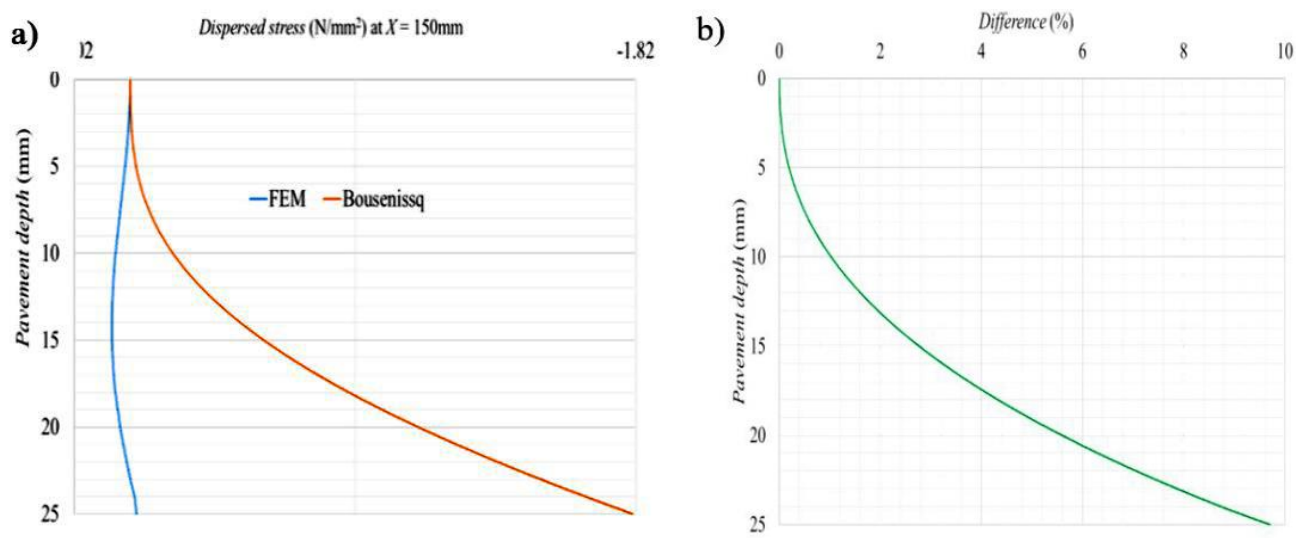

Fig. 6. a) Comparison of FE solution with Boussinesq solution b) Difference (\%) between FE solution and Boussinesq solution

The difference between the two solutions is less than $1 \%$ up to a depth of $10 \mathrm{~mm}$ measured from the top of the pavement. Between $10 \mathrm{~mm}$ and almost $20 \mathrm{~mm}$ depth, the difference is not more than $5 \%$. The maximum difference is approximately $9.5 \%$ at the base of the pavement ( 25 $\mathrm{mm}$ depth). Because the Boussinesq solution is developed for semi-space and results provided by it are more appropriate for small depths, the FE approach used is assumed satisfactory for the intended parameter study.

\subsection{Assumed Distribution of Dispersed Load}

As seen from Fig. 4 and Fig. 7, the distribution of the dispersed stress at the base of the pavement can be assumed to be trapezoidal, characterized using the dimensions $f, e_{1}$ and $e_{2}$ given in Fig. 7 .

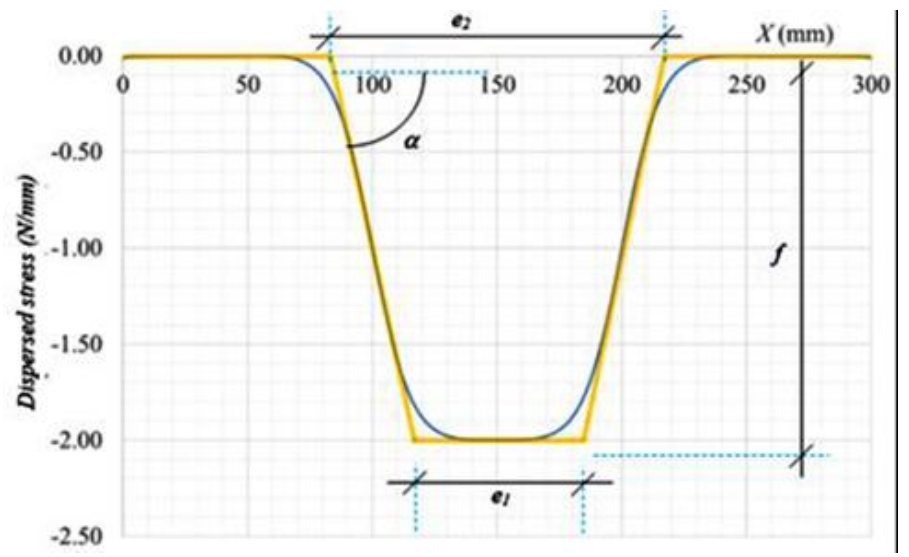

Fig. 7 Distribution of dispersed stress at the pavement base

Here $f, e_{1}$ and $e_{2}$ are clearly functions of wheel load, wheel breadth, elasticity modulus, Poisson ratio, width, and thickness of pavement. Using the default values of parameters $f, e_{1}$ and $e_{2}$ results 
in $-2 \mathrm{~N} / \mathrm{mm}(-1.9979 \approx-2), 69 \mathrm{~mm}$, and $134 \mathrm{~mm}$ respectively, which are derived from Fig. 7 using the Fortran code provided in Appendix 1. The measured value of $\alpha$ is $3.52^{\circ}$. However, $f, e_{1}$ and $e_{2}$ are not totally independent and the area of the trapezoid must be equal to the wheel load as per Eq.6.

$$
\text { Wheel load }=-f \cdot\left(\frac{e_{1}+e_{2}}{2}\right)
$$

If Eq. 6 is not satisfied, it is advisable to keep $f$ and $e_{1}$ the same and justify the value of $e_{2}$, such that Eq. 6 holds. In the subsequent sections, $f, e_{1}$ and $e_{2}$ are obtained as functions of the intended research parameters.

\subsection{Effect of Parameters on $f, e_{1}$ and $e_{2}$}

\subsubsection{Effect of Elasticity Modulus on $f_{\text {, }} e_{1}$ and $e_{2}$}

The elasticity modulus of the pavement $\left(E_{P}\right)$ is varied from $1 \mathrm{GPa}$ to $100 \mathrm{GPa}$, while other parameter values are kept constant. From the results shown in Fig. 8, it is apparent that $f, e_{1}$ and $e_{2}$ are independent on the elasticity modulus of the pavement. The values of dispersed stress in Fig. 8 in all scenarios are so same, that all three curves for $E=1,10$ and $100 \mathrm{GPa}$ are overlapped.

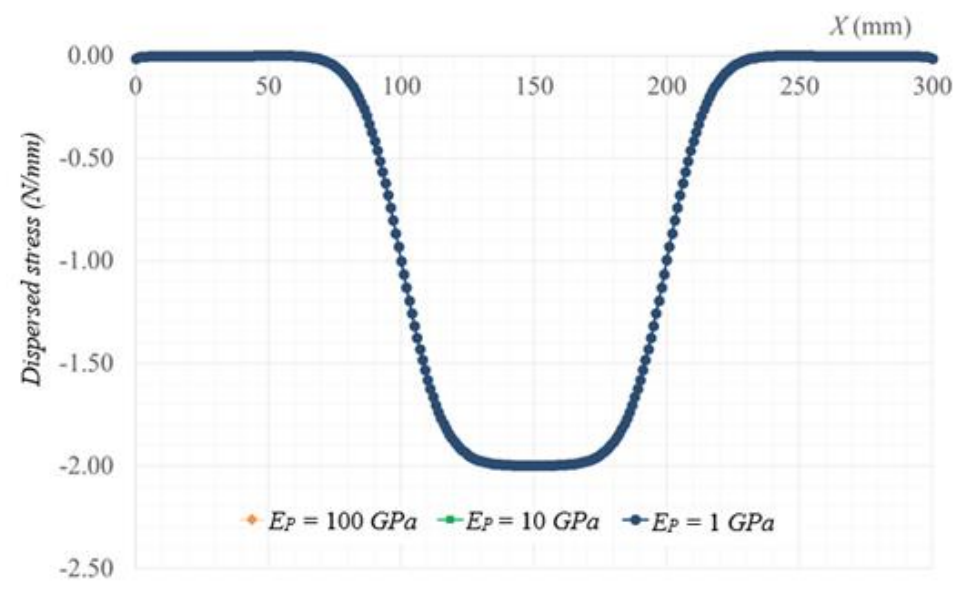

Fig. 8 Dispersed stress at the base of pavement for varying elasticity modulus 


\subsubsection{Effect of Poisson's Ratio on $f, e_{1}$ and $e_{2}$}

As seen in Fig. 9, the effect of Poisson's ratio on $f, e_{1}$ and $e_{2}$ is very slight, that it can readily be ignored as a parameter affecting on $f, e_{1}$ or $e_{2}$.

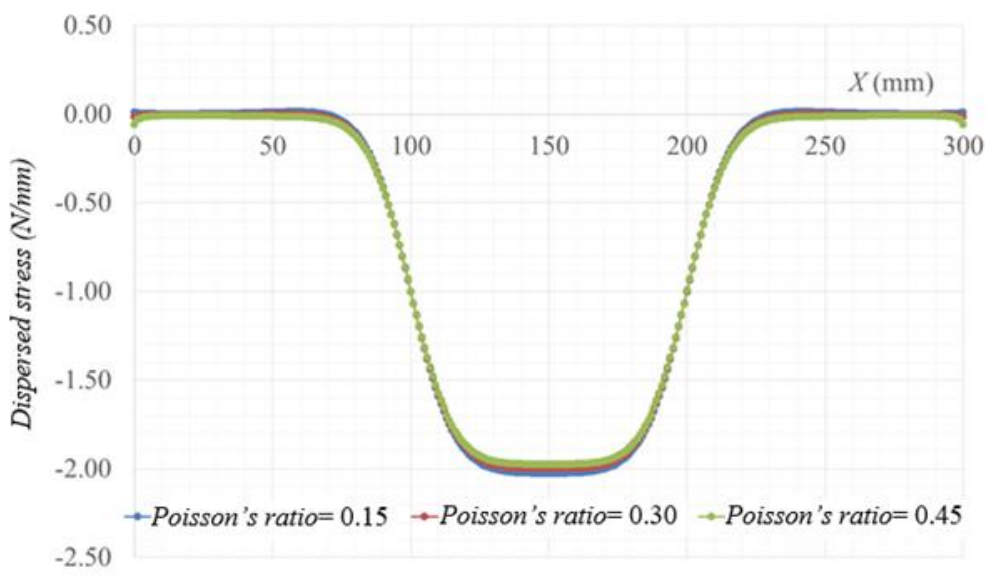

Fig. 9 Dispersed stress at the base of pavement for varying Poisson's ratio.

\subsubsection{Effect of Pavement Width on $f_{1} e_{1}$ and $e_{2}$}

The effect of pavement width on $f, e_{1}$ and $e_{2}$ is shown in Fig. 10. It is clear that widths less than $150 \mathrm{~mm}$ lead to stress concentrations at the two edges of the pavement. At the same time, varying the width from $150 \mathrm{~mm}$ to $400 \mathrm{~mm}$ has almost no effect on the magnitude and distribution of the dispersed stress. Two conclusions may be drawn from Fig. 10: First, the width of the pavement should be at least one and a half times the wheel breadth (Pavement width $\geq 1.5$.Wheel breadth). Second, varying the width above this value has no effect on $f, e_{1}$ and $e_{2}$.

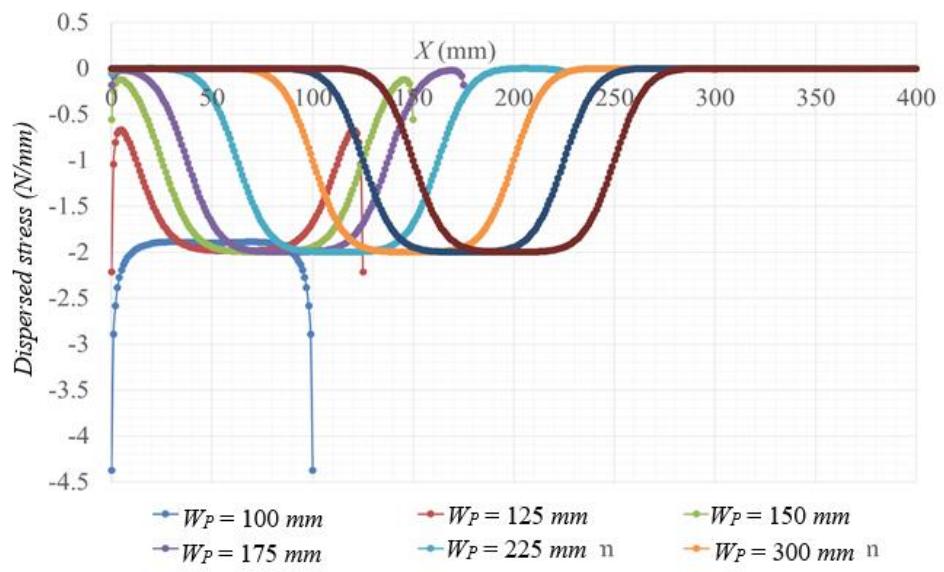

Fig. 10 Dispersed stress depending on the pavement width. 


\subsubsection{Effect of Wheel Load on $f_{1} e_{1}$ and $e_{2}$}

The variation of the dispersed load depending on wheel load is given in Fig. 11. $e_{1}$ and $e_{2}$ derived from the curves are all the same, meaning that the wheel load has no effect on them.

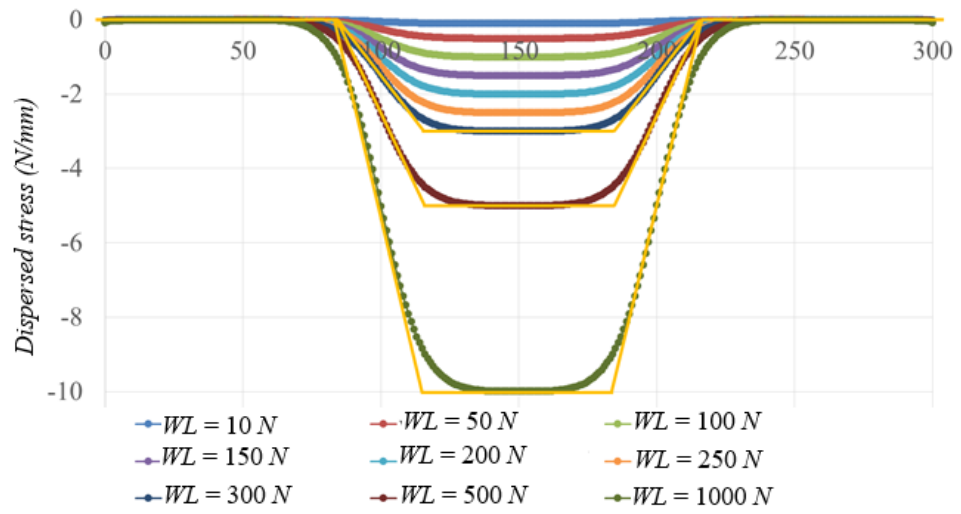

Fig. 11 Dispersed stress depending on the value of wheel load.

Nonetheless, $f$ is directly proportional to the wheel load as given in Fig. 12, if the effect of the remaining parameters (wheel breadth and pavement thickness) are ignored.

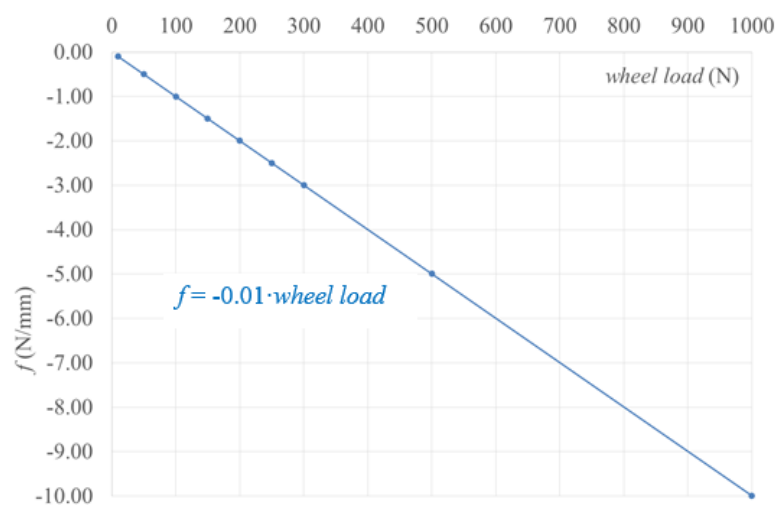

Fig. 12 Variation of $f$ depending on wheel load.

According to Fig. 12, the relationship between $f$ and wheel load is linear and may be described as follows:

$$
f=-0.01 \cdot \text { wheel load }
$$

Here, it is apparent that the coefficient (0.01) comes from the ratio, Wheel Load / Wheel Breadth for all the cases. For instance, for $W_{L}=700 \mathrm{kN}, f$ derived from Fig. 12 is $7 \mathrm{~N} / \mathrm{mm}$, which is equal to $700 \mathrm{~N} / 100 \mathrm{~mm}=7 \mathrm{~N} / \mathrm{mm}$. As a result, $f$ is described using Eq. $7 \mathrm{~b}$ below.

$$
f=-\left(W_{L} / W_{B}\right) \cdot g\left(W B, T_{P}\right)
$$

where $g$ is a function of wheel breadth and pavement thickness. 


\subsubsection{Effect of Pavement Thickness on $f_{1} e_{1}$ and $e_{2}$}

As seen in Fig.13, $f, e_{1}$ and $e_{2}$, all vary depending on thickness of pavement $\left(T_{P}\right)$.

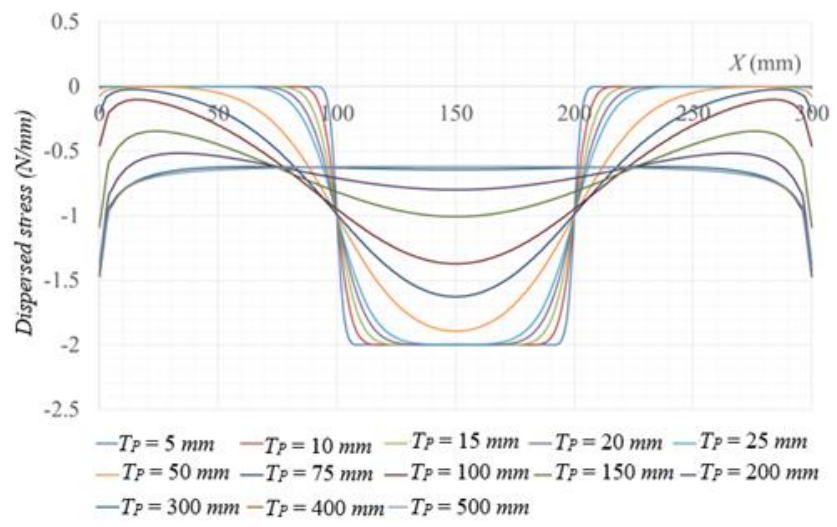

Figure 13. Dispersed stress depending on pavement thickness.

Fig. 13 indicates that starting from a thickness of $75 \mathrm{~mm}$ and up to $150 \mathrm{~mm}$, some stress concentrations develop at the edges, but in sufficiently small numbers to allow them to be ignored. However, above a thickness of $150 \mathrm{~mm}$ the number of stress concentrations becomes critical, making an applied methodology to derive f, $e_{1}$ and $e_{2}$ extremely difficult.

\subsubsection{Effect of Wheel Breadth on $f, e_{1}$ and $e_{2}$}

Effect of wheel breadth on $f, e_{1}$ and $e_{2}$ is shown in Fig. 14, from which it is deduced that they are all functions of the parameter wheel breadth as in the case of pavement thickness.

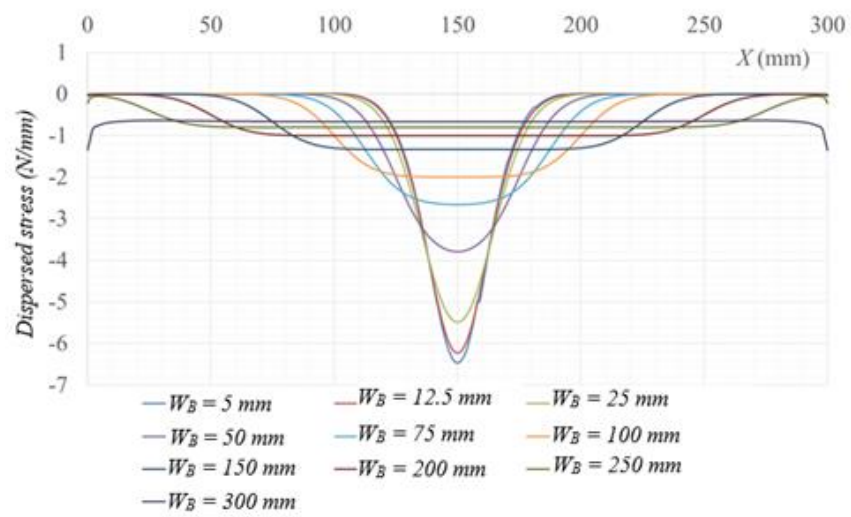

Fig. 14 Dispersed stress depending on wheel breadth.

\subsubsection{Widening Width of Pavement to Eliminate Stress Concentrations}

If the width of pavement is increased to $2 \mathrm{~m}$, the stress concentrations are reduced significantly, however they cannot be completely eliminated especially at extreme pavement thicknesses such as $1000 \mathrm{~mm}$, as observed from Fig. 15. Therefore, the pavement width of $2 \mathrm{~m}$ is taken as the default value of the parameter pavement width in the FE analyses hereafter. Since the shoulder width in highways is at least $1 \mathrm{~m}$, and half the wheel spacing is approximately $1 \mathrm{~m}$, the default pavement length $=1 \mathrm{~m}+1 \mathrm{~m}=2 \mathrm{~m}$ is seen to be realistic. 


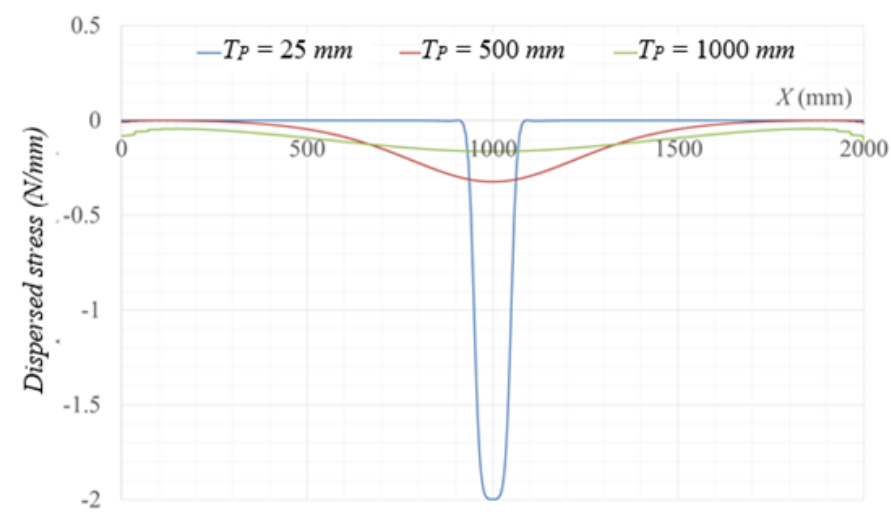

Fig.15 Stress concentrations developed for different pavement thicknesses, when pavement width is $2 \mathrm{~m}$.

\subsection{Assumed Distribution of Dispersed Load}

Because $f$ depends solely on wheel load, pavement thickness and wheel breadth, the function of $f$ is derived based on these three variables. It has already been shown that $f$ is directly proportional to wheel load according to Eq.7a, the variation of $f$ depending on wheel breadth and pavement thickness for a wheel load of $1 \mathrm{~N}$ is shown in the chart given in Fig. 15. Data tables for Figs. 16, 17 and 18 are given in Appendix 2.

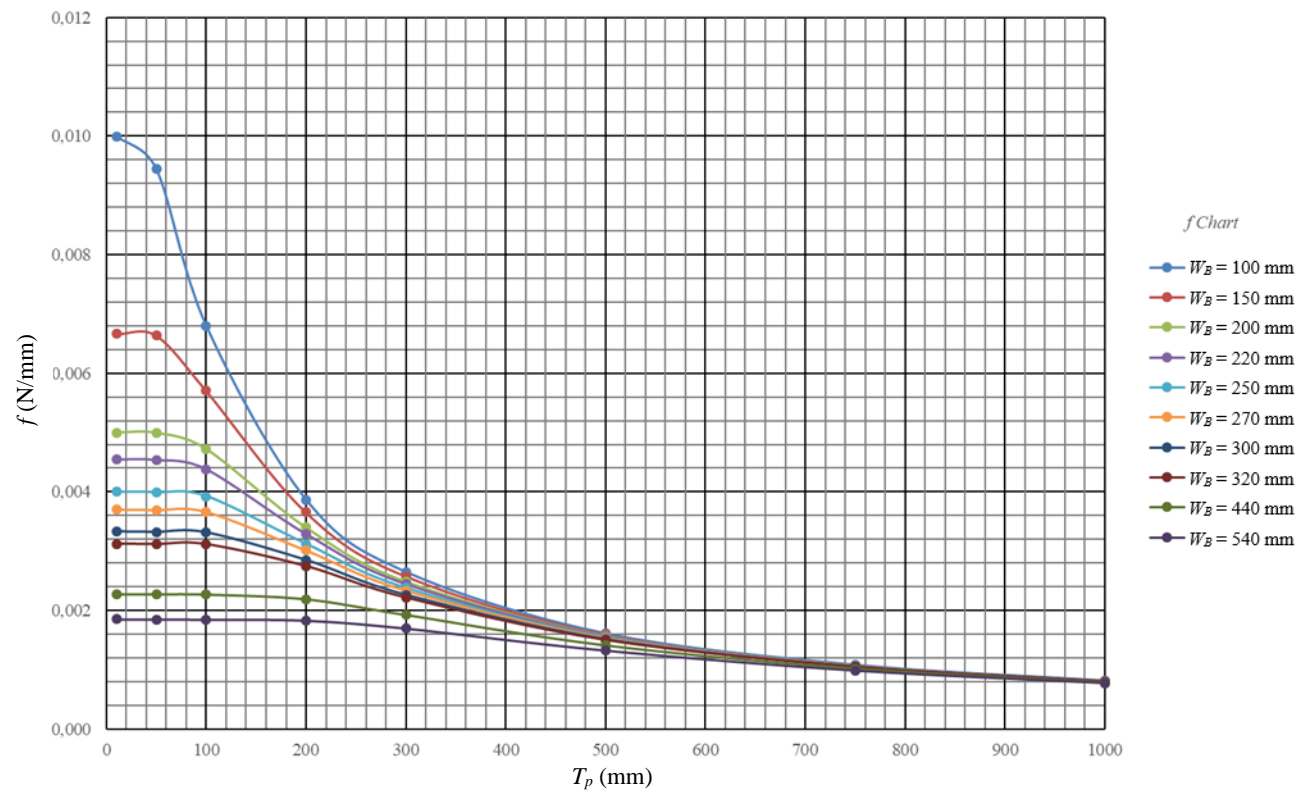

Fig. $16 f$ depending on pavement thickness $\left(T_{P}\right)$ and wheel breadth $\left(W_{B}\right)$ for wheel load $=1 \mathrm{~N}$. 


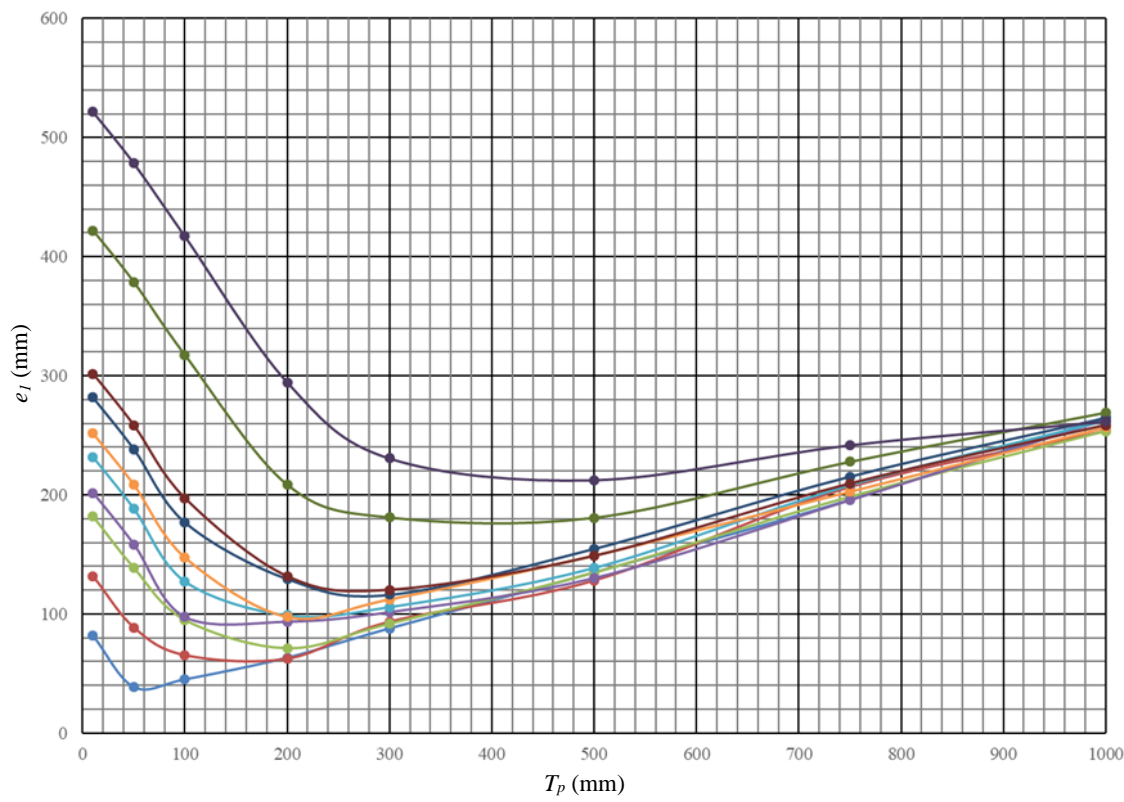

Fig. 17 Recommended values of $e_{1}$.

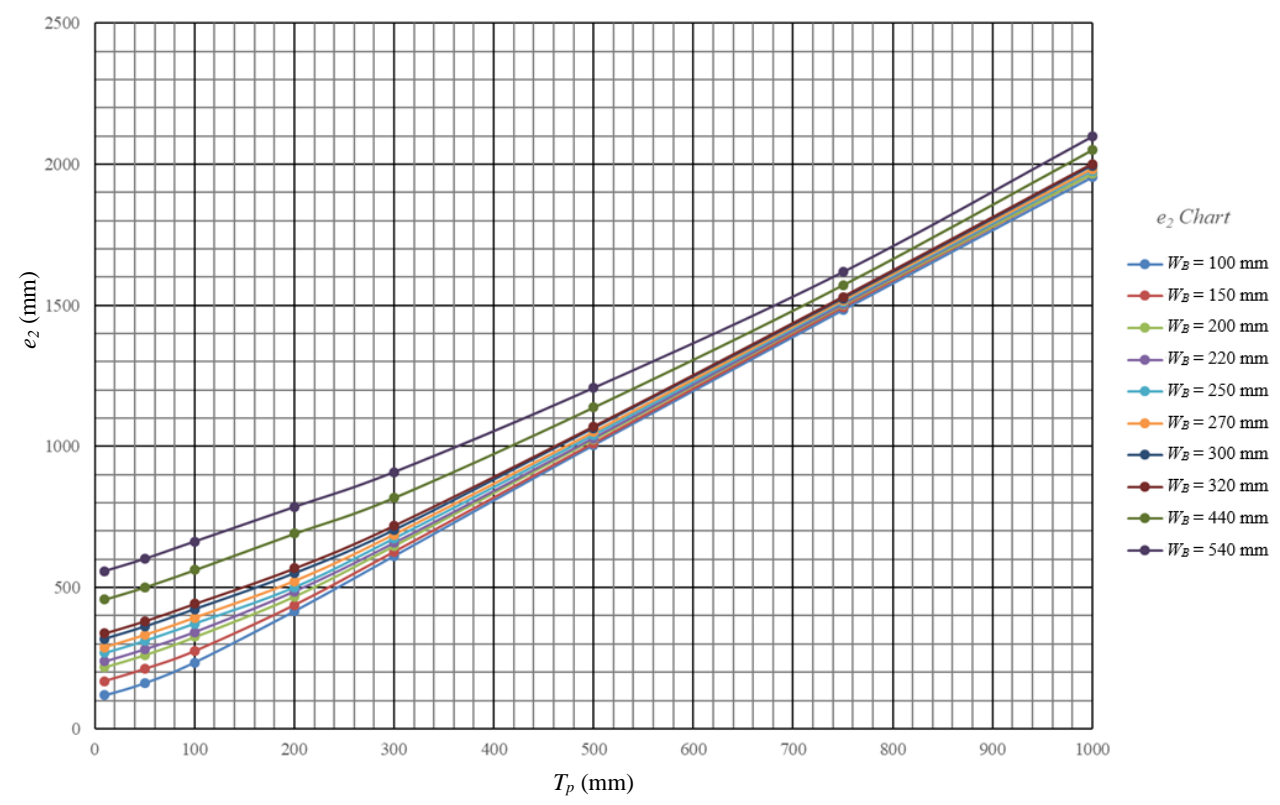

Fig. 18 Recommended values of $e_{2}$.

\section{A Numerical Example}


The method derived here is a simple hand calculation method for designing concrete (or linear elastic) pavements under axle loads. The method allows rapid and easy calculation of pavement stresses and is especially recommended for engineers unable to perform a FE-analysis due to a lack of time and software. In this section, a truck load is first selected complying with EC 3 [6] and then the magnitude and distribution of stresses developed at the bottom of the pavement are calculated using the charts derived in this study. Finally, results obtained are compared with the results obtained from an FE-analysis.

\subsection{Problem Description}

According to EC 3 [6] heavy truck vehicles are defined by,

1. Axle number and distance between axles (Table 1, column 1 and 2),

2. Frequently used axle load (Table 1, column 3),

3. Wheel load area and transverse distance between wheel loads (Column 4 of Table 1 and Table 2).

Table 1 Group of frequently used heavy truck vehicles [6].

\begin{tabular}{|c|c|c|c|}
\hline 1 & 2 & 3 & 4 \\
\hline $\begin{array}{c}\text { View of heavy truck } \\
\text { vehicle }\end{array}$ & Axle distance (m) & $\begin{array}{c}\text { Frequently used axle } \\
\text { load }(k N)\end{array}$ & Tyre type \\
\hline & 4.50 & $\begin{array}{c}90 \\
190\end{array}$ & $\begin{array}{l}\mathrm{A} \\
\mathrm{B}\end{array}$ \\
\hline & $\begin{array}{l}4.20 \\
1.30\end{array}$ & $\begin{array}{c}80 \\
140 \\
140\end{array}$ & $\begin{array}{l}\text { A } \\
\text { B } \\
\text { B } \\
\end{array}$ \\
\hline & $\begin{array}{l}3.20 \\
5.20 \\
1.30 \\
1.30\end{array}$ & $\begin{array}{c}90 \\
180 \\
120 \\
120 \\
120 \\
\end{array}$ & $\begin{array}{l}\text { A } \\
\text { B } \\
\text { C } \\
\text { C } \\
\text { C } \\
\end{array}$ \\
\hline & $\begin{array}{l}3.40 \\
6.00 \\
1.80\end{array}$ & $\begin{array}{c}90 \\
190 \\
140 \\
140\end{array}$ & $\begin{array}{l}\text { A } \\
\text { B } \\
\text { B } \\
\text { B } \\
\end{array}$ \\
\hline & $\begin{array}{l}4.80 \\
3.60 \\
4.40 \\
1.30\end{array}$ & $\begin{array}{c}90 \\
180 \\
120 \\
110 \\
110\end{array}$ & $\begin{array}{l}\text { A } \\
\text { B } \\
C \\
C \\
C\end{array}$ \\
\hline
\end{tabular}


Table 2 Wheel contact areas [6].

A

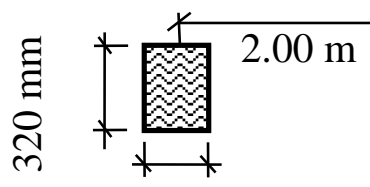

$220 \mathrm{~mm}$

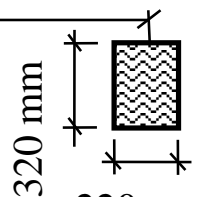

$220 \mathrm{~mm}$

B

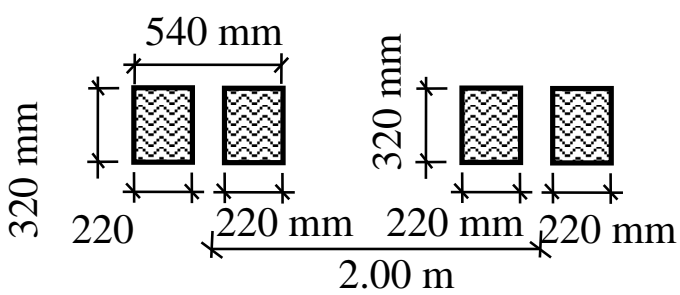

$\mathrm{C}$

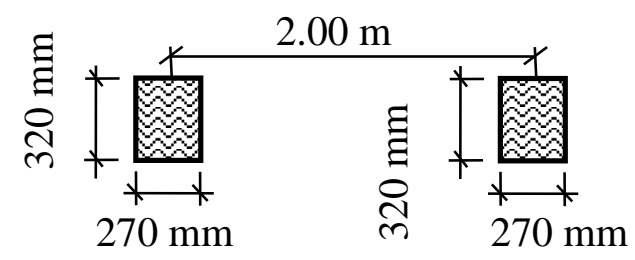

From Table 1, the heavy vehicle in the second row is selected as the truck design load. A C10 concrete pavement without reinforcement is selected. The soil strength is taken as $300 \mathrm{kPa}$. The thickness of the concrete pavement must be justified to keep the maximum stress at the pavement base lower than the soil strength. 


\subsection{Solution}

The truck loads in the longitudinal and transverse directions are given in Figs. 19, 20, and 21.

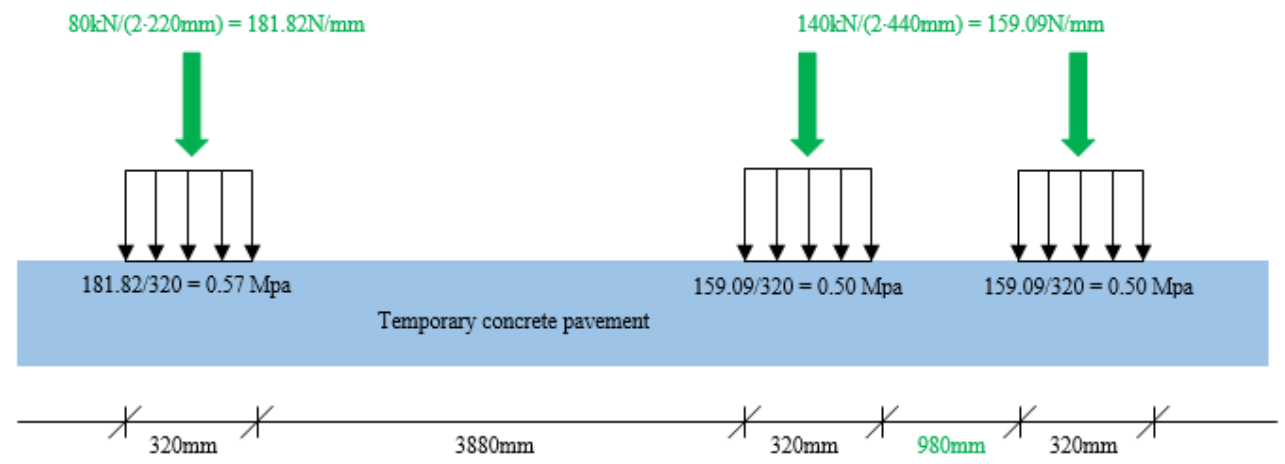

Fig. 19 Truck loading in longitudinal direction.

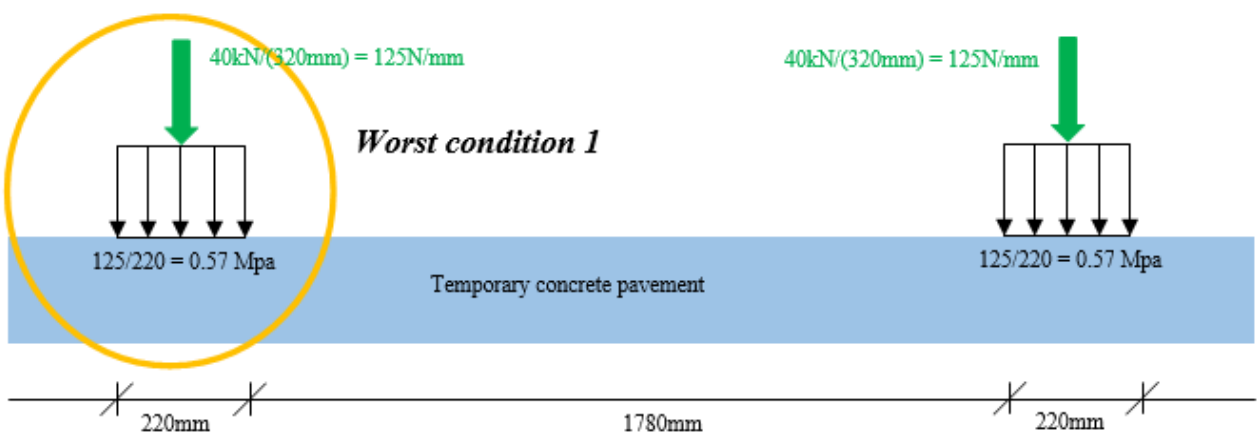

Fig. 20 Truck loading in transverse (1 $1^{\text {st }}$ axle) direction.

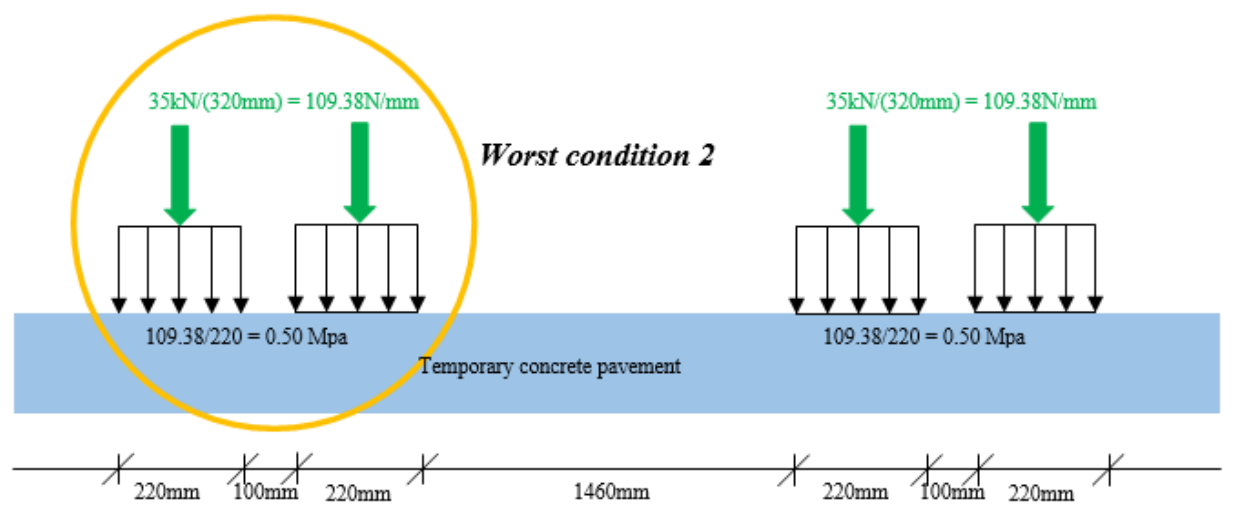

Fig. 21 Truck loading in transverse $\left(2^{\text {nd }}\right.$ or $3^{\text {rd }}$ axle $)$ direction. 


\subsubsection{Solution of Worst Condition 1}

Because the worst condition 1 is composed of a single wheel load, only the maximum stress at the pavement base $(f)$ is calculated, and the shape of dispersed stress $\left(e_{1}\right.$ and $\left.e_{2}\right)$ is not required. From Fig. 16, $f$ is determined as follows:

$125 \cdot f$ (wheel breadth $=220 \mathrm{~mm}$, pavement thickness $=$ ?) $\leq$ soil strength $=0.30 \mathrm{MPa}$

$f($ wheel breadth $=220 \mathrm{~mm}$, pavement thickness $=?) \leq 0.0024 \mathrm{MPa}$

From Figure 16, $f=0.0022 \mathrm{MPa} \rightarrow T_{P}=320 \mathrm{~mm}=32 \mathrm{~cm}$

\subsubsection{Solution of Worst Condition 2}

Because the worst condition 2 is composed of two wheel loads, two maximum stresses at the bottom of the pavement $(f)$ are calculated together with their corresponding distributions $\left(e_{1}\right.$ and $e_{2}$ for both). However, since the two wheels are similar, this problem reduces to finding one set of $f, e_{1}$ and $e_{2}$ and the maximum stress in the interaction zone. From Fig. 16, $f$ is determined as follows:

109.38 $f$ (wheel breadth $=220 \mathrm{~mm}$, pavement thickness $=$ ?) $\leq$ soil strength $=0.30 \mathrm{MPa}$

$f \leq 0.0027 \mathrm{MPa}$

From Fig. $16 f=0.0023 \mathrm{MPa} \rightarrow T_{P}=240 \mathrm{~mm}=24 \mathrm{~cm}$ and

$109.38 \cdot f=109.38 \cdot 0.0023=0.25 \mathrm{MPa} \leq$ soil strength $=0.30 \mathrm{MPa}$

From Fig. 17, $e_{1}$ is determined as follows:

$e_{1}($ wheel breadth $=220 \mathrm{~mm}$, pavement thickness $=240 \mathrm{~mm})=95 \mathrm{~mm}$

From Fig. 18, $e_{2}$ is determined as follows:

$e_{2}($ wheel breadth $=220 \mathrm{~mm}$, pavement thickness $=240 \mathrm{~mm})=550 \mathrm{~mm}$

According to these values Fig. 22 is drawn and the maximum stress in the interaction zone is calculated. Using Fig. 22 and the affinity between triangles, this maximum stress is calculated as:

$2 \cdot 0.0012 \mathrm{MPa}=0.0024 \mathrm{MPa}$

Since

Max. stress for $1 \mathrm{~N}=0.0024 \mathrm{MPa}<0.0027 \mathrm{MPa}$ or,

Max. stress for two adjacent wheel load (Worst condition 2) =

$=109.38 \cdot 0.0024=0.26 \mathrm{MPa}<0.30 \mathrm{MPa}=$ Soil strength,

$24 \mathrm{~cm}$ pavement thickness is enough under selected truck loading. 


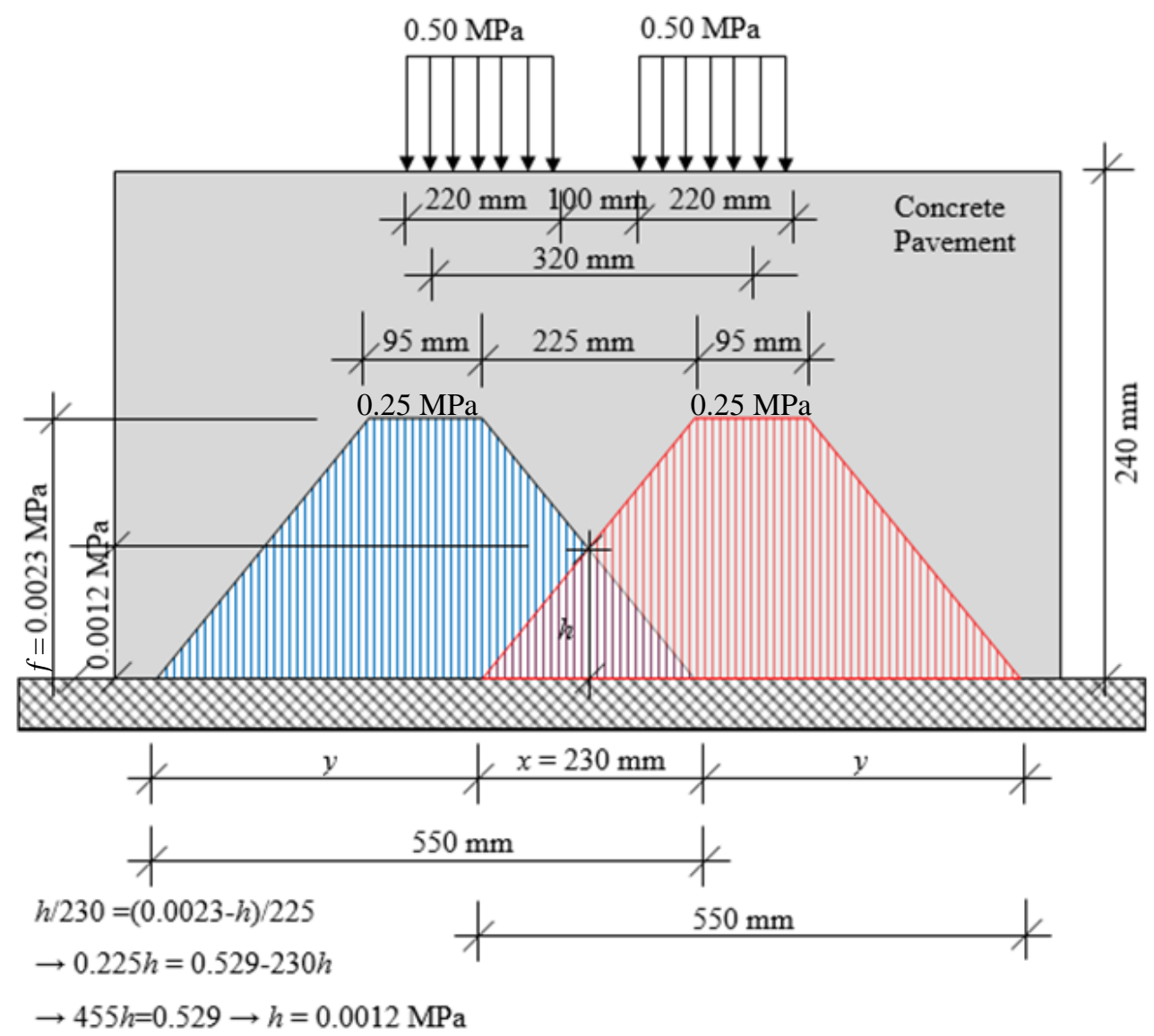

Fig. 22 Interacted dispersed stresses for pavement thickness $=24 \mathrm{~cm}$ and wheel breadth $=$ $220 \mathrm{~mm}$.

\section{Conclusion}

It is seen that the distribution of dispersed stress can be assumed to be trapezoidal, provided that stress concentrations that may develop at the edges are ignored. The generally assumed $45^{\circ}$ angle for stress dispersal is not correct and moreover yields to unsafe pavement thickness values, because the dispersed stress does not remain uniform, but approximately trapezoidal. Thus, the maximum stress developed at the pavement base is aligned with the mid-point of the wheel breadth. The elasticity modulus and Poisson's ratio of the linear elastic pavement have no effect on the stress dispersal. If the width of the linear elastic pavement is greater than 1.5 times wheel breadth, then the width of the linear elastic pavement has also no effect on the stress dispersal. In summary, $f$ is a function of wheel load, wheel breadth, and thickness of pavement, while $e_{1}$ and $e_{2}$ are functions of only wheel breadth and pavement thickness. Charts and tables derived using FE analysis have been verified, and the application of the proposed design method for linear elastic rigid (temporary or permanent concrete) pavements without reinforcement has been explained by means of a numerical example. 


\section{References}

[1] Groenendijk, J. Accelerated testing and surface cracking of asphaltic concrete pavement.(Ph.D. Dissertation, Delft University of Technology, Delft, 1998.

[2] Pottinger, M.G. The Three-Dimensional Contact Patch Stress Field of Solid and Pneumatic Tires. Tire Science and Technology, 1992; 20: 3-32. https://doi.org/10.2346/1.2139508

[3] Tielking, J.K, Abraham, M. A. Measurement of Truck Tire Footprint Pressures. Journal of the Transportation Research Board, 1994; 1435: 92-99.

[4] Beer, M. de. Measurement of tyre/pavement interface stresses under moving wheel loads. Heavy Vehicle Systems, Special Series, Int. J. of Vehicle Design, 1996; 3: 97-115.

[5] Jong, F. B. P. de (2007). Renovation techniques for fatigue cracked orthotropic steel bridge decks.-Ph.D. Dissertation, Delft University of Technology, Delft.

[6] Eurocode 3 Part 3. Actions on Structures, Brussel, Belgium, 2006.

[7] Li, Y., Song, G, Cai, J. Mechanical Response Analysis of Airport Flexible Pavement Above Underground Infrastructure Under Moving Wheel Load. Geotech Geol Eng, 2017; 35: 22692275. https://doi.org/10.1007/s10706-017-0242-8

[8] Swanson Analysis System. ANSYS, USA, 2017.

[9] Timoshenko, S, Goodier, J. N. Theory of Elasticity, McGraw-Hill, New York, USA, 1969. 


\section{Appendices}

\section{Appendix 1}

The Fortran code is given below.

IMPLICIT REAL*8 (A-H,O-Z)

CHARACTER*20 DAT,out1

CHARACTER $* 1$ DA(20)

parameter $(\mathrm{imax}=80000, \mathrm{nmax}=2600000)$

double precision $\mathrm{dp}(\mathrm{nmax})$

dimension fslp(3)

integer in(imax),nslope

WRITE $(*, *)$ 'Name of The Data File'

$\operatorname{READ}(*, 550)$ DA

OPEN $(4, F I L E=' D N A M E ')$

$\mathrm{K}=0$

D0 $1 \mathrm{I}=1,20$

IF(DA(I).EQ.' ')GO TO 2

$1 \mathrm{~K}=\mathrm{K}+1$

2 WRITE(4, $\left.{ }^{*}\right) " '$,(DA(I),I=1,K),"'"

WRITE $\left(4,{ }^{*}\right)^{\prime \prime ",(D A(I), I=1, K), ' . O U T ' " ~}$

REWIND 4

$\operatorname{READ}\left(4,{ }^{*}\right) \mathrm{DAT}$

$\operatorname{READ}\left(4,{ }^{*}\right)$ out1

CLOSE(4,STATUS='DELETE')

550 FORMAT(20A1)

$\operatorname{OPEN}(5, \mathrm{FILE}=\mathrm{DAT})$

OPEN(10,FILE=out1)

$\mathrm{C}^{* * * *}$

$\operatorname{read}(5, *)$ numdata ! number of data at the curve

c data $1=\operatorname{dp}(1)$

$\mathrm{i} 1=1+$ numdata*2

call data_read(numdata,dp(1))

c slope_x $=\mathrm{dp}(\mathrm{i} 1)$

$\mathrm{i} 2=\mathrm{i} 1+3$

c slope_x $=\mathrm{dp}(\mathrm{i} 2)$

$i 3=i 2+3$

c islope_p $=$ in $(1)$

$\mathrm{n} 1=1+3$

call max_min(numdata,dp(1),dp(i1),dp(i2),in(1))

nslope $=1$

call slope_cal(numdata,dp(1),dp(i1),dp(i2),in(1),fslp(1))

call calc_a_b(numdata,dp(1),dp(i1),dp(i2),in(1),fslp(1))

$\mathrm{aa}=1$.

stop

end 
subroutine calc_a_b(numdata,data1,slope_x,slope_y,islope_p,fslp)

IMPLICIT REAL*8 (A-H,O-Z)

Dimension data1(numdata,2),slope_x(3),slope_y(3),fslp(3)

Integer islope_p(3)

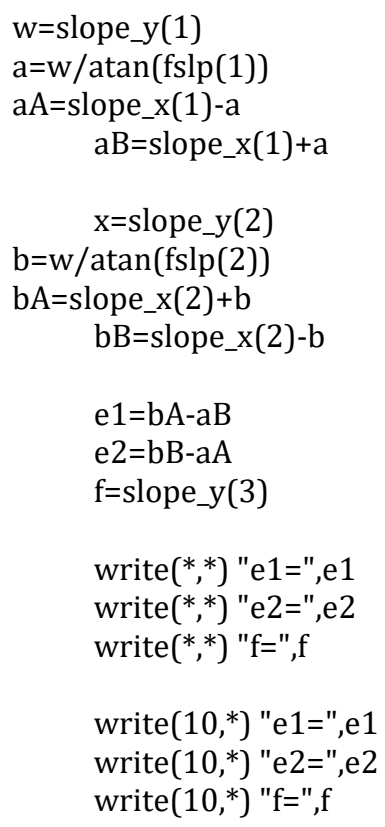

return

end

subroutine slope_cal(numdata,data1,slope_x,slope_y,islope_p,fslp)

IMPLICIT REAL*8 (A-H,O-Z)

Dimension data1(numdata,2),slope_x(3),slope_y(3),fslp(3)

Integer islope_p(3),htype

htype=2 ! "1" for h, "2" for $2 \mathrm{~h}$

if (htype.EQ.1) then

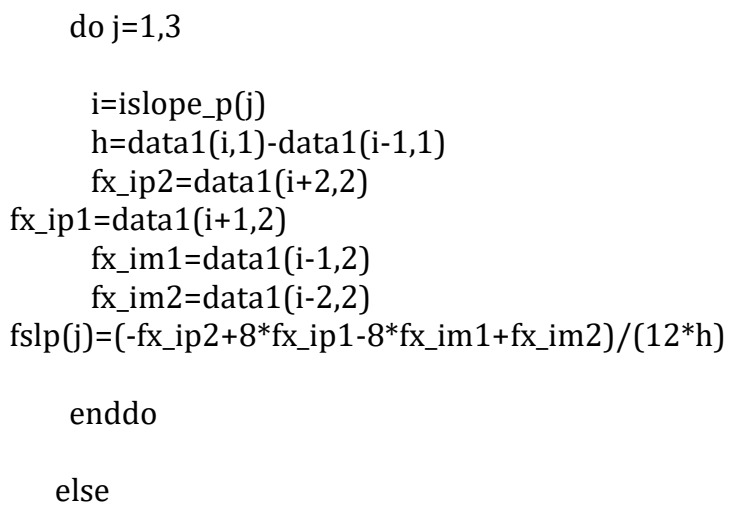




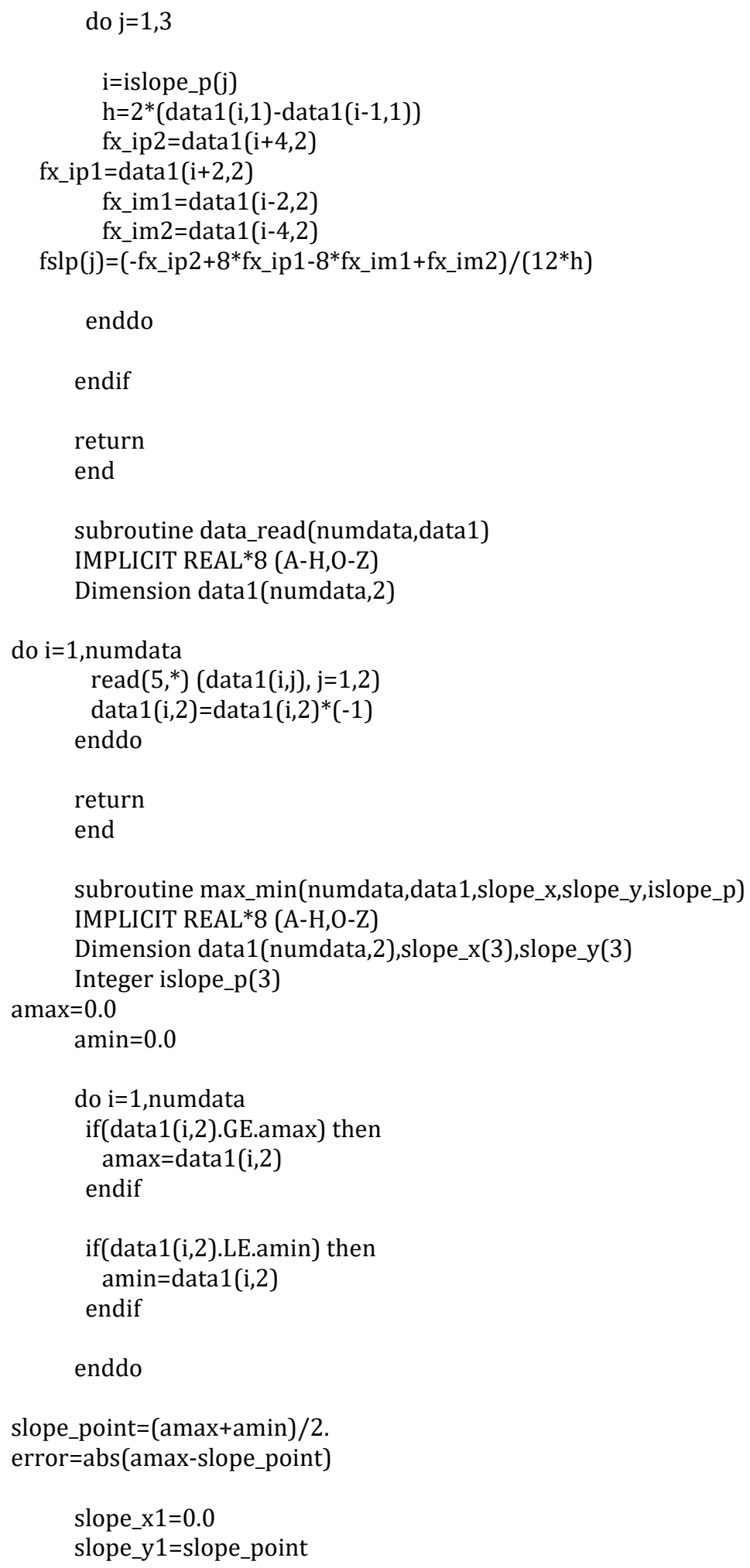




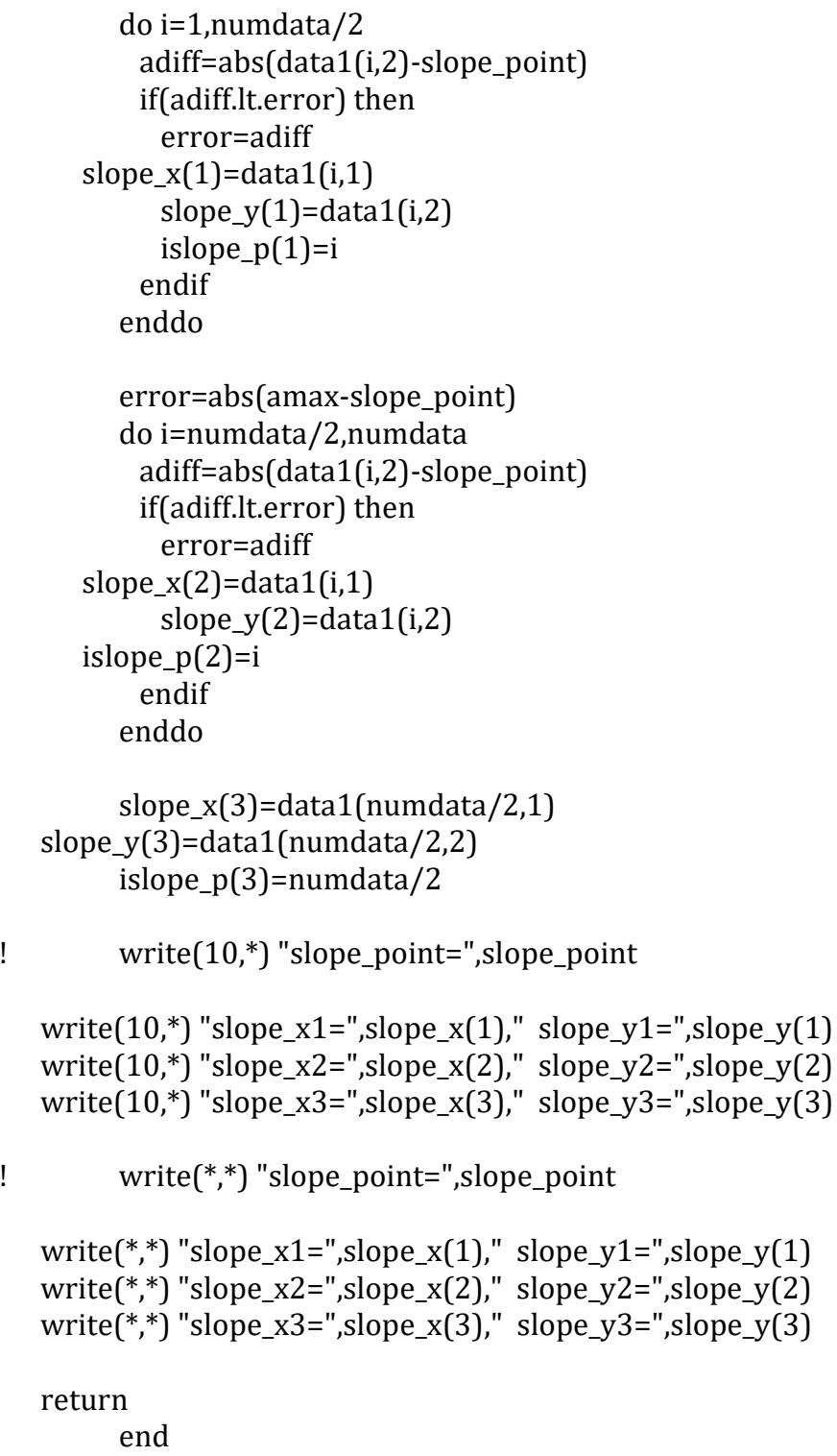




\section{Appendix 2}

Data tables for Figs. 16, 17 and 18 are provided below respectively.

Table 3. Data Table ( $f$ values) for Fig. 16.

\begin{tabular}{|c|c|c|c|c|c|c|c|c|c|c|}
\hline $\begin{array}{l}T p \\
(\mathrm{~mm})\end{array}$ & $\begin{array}{c}W_{B}=100 \\
\mathrm{~mm}\end{array}$ & $\begin{array}{c}w B=150 \\
m m\end{array}$ & $\begin{array}{c}w B=200 \\
m m\end{array}$ & $\begin{array}{c}w B=220 \\
m m\end{array}$ & $\begin{array}{c}w B=250 \\
m m\end{array}$ & $\begin{array}{c}w B=270 \\
m m\end{array}$ & $\begin{array}{c}w B=300 \\
m m\end{array}$ & $\begin{array}{c}w B=320 \\
m m\end{array}$ & $\begin{array}{c}w B=440 \\
m m\end{array}$ & $\begin{array}{c}w B=540 \\
m m\end{array}$ \\
\hline 10 & 0.009996 & 0.006666 & 0.005000 & 0.004545 & 0.004000 & 0.003704 & 0.003333 & 0.003125 & 0.002273 & 0.001852 \\
\hline 50 & 0.009446 & 0.006637 & 0.004993 & 0.004537 & 0.003990 & 0.003695 & 0.003326 & 0.003119 & 0.002271 & 0.001851 \\
\hline 100 & 0.006803 & 0.005707 & 0.004720 & 0.004379 & 0.003927 & 0.003664 & 0.003318 & 0.003117 & 0.002268 & 0.001847 \\
\hline 200 & 0.003870 & 0.003656 & 0.003399 & 0.003290 & 0.003124 & 0.003014 & 0.002852 & 0.002747 & 0.002189 & 0.001831 \\
\hline 300 & 0.002649 & 0.002579 & 0.002488 & 0.002447 & 0.002382 & 0.002336 & 0.002265 & 0.002217 & 0.001924 & 0.001697 \\
\hline 500 & 0.001610 & 0.001594 & 0.001573 & 0.001563 & 0.001546 & 0.001534 & 0.001515 & 0.001501 & 0.001409 & 0.001323 \\
\hline 750 & 0.001081 & 0.001076 & 0.001070 & 0.001067 & 0.001061 & 0.001058 & 0.001051 & 0.001047 & 0.001015 & 0.000984 \\
\hline 1000 & 0.000815 & 0.000813 & 0.000810 & 0.000809 & 0.000806 & 0.000805 & 0.000802 & 0.000800 & 0.000786 & 0.000772 \\
\hline
\end{tabular}


Table 4. Data Table ( $e_{1}$ values) for Fig. 17.

\begin{tabular}{|c|c|c|c|c|c|c|c|c|c|c|}
\hline$\underset{(m m)}{T p}$ & $\begin{array}{c}W_{B}=100 \\
\mathrm{~mm}\end{array}$ & $\begin{array}{c}w B=150 \\
m m\end{array}$ & $\begin{array}{c}w B=200 \\
m m\end{array}$ & $\begin{array}{c}w B=220 \\
m m\end{array}$ & $\begin{array}{c}w B=250 \\
m m\end{array}$ & $\begin{array}{c}w B=270 \\
m m\end{array}$ & $\begin{array}{c}w B=300 \\
m m\end{array}$ & $\begin{array}{c}w B=320 \\
m m\end{array}$ & $\begin{array}{c}w B=440 \\
m m\end{array}$ & $\begin{array}{c}w B=540 \\
\mathrm{~mm}\end{array}$ \\
\hline 10 & 81.8 & 131.8 & 181.8 & 201.8 & 231.8 & 251.8 & 281.8 & 301.8 & 421.8 & 521.8 \\
\hline 50 & 38.6 & 88.5 & 138.5 & 158.4 & 188.4 & 208.5 & 238.4 & 258.4 & 378.4 & 478.4 \\
\hline 100 & 45.1 & 65.3 & 94.8 & 97.5 & 127.4 & 147.4 & 177.0 & 197.2 & 317.2 & 417.1 \\
\hline 200 & 63.4 & 62.3 & 71.1 & 93.6 & 99.0 & 97.5 & 129.6 & 131.8 & 208.6 & 294.6 \\
\hline 300 & 88.0 & 93.5 & 91.8 & 101.6 & 106.0 & 112.3 & 116.4 & 120.4 & 181.2 & 230.8 \\
\hline 500 & 13.0 & 12.1 & 134.6 & 130.2 & 138.8 & 149.0 & 155.0 & 148.9 & 180.9 & 212.6 \\
\hline 750 & 196.1 & 206.7 & 198.4 & 195.4 & 208.2 & 202.7 & 215.5 & 209.6 & 227.8 & 241.9 \\
\hline 1000 & 265.5 & 253.9 & 253.5 & 262.8 & 262.2 & 256.6 & 264.7 & 258.7 & 268.9 & 261.7 \\
\hline
\end{tabular}


Table 5. Data Table ( $e_{2}$ values) for Fig. 18.

\begin{tabular}{|c|c|c|c|c|c|c|c|c|c|c|}
\hline$\underset{(m m)}{T p}$ & $\begin{array}{c}W_{B}=100 \\
\mathrm{~mm}\end{array}$ & $\begin{array}{c}w B=150 \\
m m\end{array}$ & $\begin{array}{c}w B=200 \\
m m\end{array}$ & $\begin{array}{c}w B=220 \\
m m\end{array}$ & $\begin{array}{c}w B=250 \\
m m\end{array}$ & $\begin{array}{c}w B=270 \\
m m\end{array}$ & $\begin{array}{c}w B=300 \\
\mathrm{~mm}\end{array}$ & $\begin{array}{c}w B=320 \\
m m\end{array}$ & $\begin{array}{c}w B=440 \\
m m\end{array}$ & $\begin{array}{c}w B=540 \\
m m\end{array}$ \\
\hline 10 & 118.2 & $16 ., 2$ & 218.2 & 238.2 & 268.2 & 288.2 & 318.2 & 338.2 & 458.2 & 558.2 \\
\hline 50 & 161.4 & 211.5 & 261.5 & 281.6 & 311.6 & 331.5 & 361.6 & 381.6 & 501.6 & 601.6 \\
\hline 100 & 234.9 & 274.7 & 325.2 & 342.5 & 372.6 & 392.6 & 423.0 & 442.8 & 562.8 & 662.9 \\
\hline 200 & 416.6 & 437.7 & 468.9 & 486.4 & 501.0 & 522.5 & 550.4 & 568.2 & 691.4 & 785.4 \\
\hline 300 & 612.0 & 626.5 & 648.2 & 658.4 & 674.0 & 687.7 & 703.6 & 719.6 & 818.8 & 909.2 \\
\hline 500 & 100.0 & 1011.9 & 1025.4 & 1029.8 & 104.2 & 1051.0 & 106.0 & 1071.1 & 1139.1 & 1207.4 \\
\hline 750 & 1483.9 & 1493.3 & 1501.6 & 1504.6 & 151.8 & 1517.3 & 1524.5 & 1530.4 & 1572.2 & 1618.1 \\
\hline 1000 & 1954.5 & 1966.1 & 1966.5 & 1977.2 & 1977.8 & 1983.4 & 1995.3 & 2001.3 & 2051.1 & 2098.3 \\
\hline
\end{tabular}

